Volume 1, Issue 2, pages 129-146

\title{
Microcontroller Based Simple Water Flow Rate Control System to Increase the Efficiency of Solar Energy Water Distillation
}

\author{
Elang Parikesit ${ }^{1, *}$, Wibowo Kusbandono ${ }^{2}$, FA. Rusdi Sambada ${ }^{2}$ \\ ${ }^{1}$ Politeknik Mekatronika Sanata Dharma, Yogyakarta, Indonesia \\ ${ }^{2}$ Department of Mechanical Engineering, Faculty of Science and \\ Technology, Sanata Dharma University, Yogyakarta, Indonesia \\ *Corresponding Author: elang@pmsd.ac.id
}

(Received 03-05-2019; Revised 08-06-2019; Accepted 08-06-2019)

\begin{abstract}
The current problem of solar energy water distillation is in its low efficiency. Low efficiency is caused by inefficient water evaporation processes. Increasing the efficiency of water evaporation is done by controlling the rate of water entering into the absorber. The commonly used mechanical control system still has weaknesses such as the instability of the water entering the absorber. This causes less effective evaporation of water so that the resulting distillation efficiency is not optimal. The water rate input system for distillation in this study is based on a simple microcontroller. The microcontroller-based input water rate control system allows the rate of input water with a small but continuous flow rate so that the water evaporation process can be more effective. This study aims to improve the efficiency of solar energy water distillation by increasing the efficiency of the water evaporation process through controlling the flow rate of water inlet. The research was carried out by the experimental method. The parameters varied were: the rate of input water which was $0.3 l$ /hour,
\end{abstract}




\section{International Journal of Applied Sciences and Smart Technologies}

Volume 1, Issue 2, pages 129-146

p-ISSN 2655-8564, e-ISSN 2685-9432

$0.5 \mathrm{l}$ /hour and $1.2 \mathrm{l}$ /hour. Parameters measured in this study were: (1) temperature of absorber, (2) temperature of the cover glass , (3) temperature of cooling water, (4) input water temperature, (5) ambient air temperature, (6) distilled water results, (7) solar energy coming in and (8) time of recording data. The results showed that the production of distillation water using microcontroller-based water rate control was a maximum of $523 \%$ compared to the model without water rate control at a water flow rate of 0.3 liters / hour, with distillation efficiency of $66 \%$. From the results of this study it can also be concluded that microcontroller based water flow rate controller is more stable than mechanical water flow controller, especially in small flow.

Keywords: microcontroller, rate of input water, distillation of water, solar energy

\section{Introduction}

Clean water is one of the basic needs of every living thing, but there are still many regions that do not have enough clean water supply, even though the water supply is abundant. The river area is one example that the area has abundant water supply, but there is still a small supply of clean water. The water supply in the area has been contaminated with a lot of dissolved harmful substances. Therefore, a water purification process is needed in one of the processes using distillation. In the distillation process, there are two main processes, namely evaporation and condensation. Factors that can improve the evaporation process include expanding the surface of the liquid, flowing air over the surface, reducing pressure and by heating liquid. While condensation factors, namely temperature, pressure and humidity. The water distillation process starts from evaporation of contaminated water and then condenses on the cover glass. Evaporation does not carry contaminated substances, so the condensed water is suitable for consumption.

The problems that exist in the distillation of solar energy water are the low performance. This is due to the lack of effective evaporation and condensation 


\section{International Journal of Applied Sciences and Smart Technologies}

Volume 1, Issue 2, pages 129-146

p-ISSN 2655-8564, e-ISSN 2685-9432

processes. The type of distillation that is widely used is the type of tube absorber and the type of fabric absorber. The type of absorber tub is the simplest type of distillation, but the performance produced by this type is among the lowest. The low performance of distillation type absorber tub due to the amount of mass of water that is quite a lot in the tub resulting in the evaporation process does not take place quickly. The type of fabric absorber has better performance than the type of tub absorber. This is due to the type of fabric absorber, the water that will be distilled is flowed to the fabric so that it will produce a thin layer of water on the fabric and cause the water to evaporate faster.

The important thing to get a thin layer on the fabric is to regulate the flow rate of water entering the absorber. Setting the flow rate must be able to produce a constant flow at a small flow rate. Setting the flow of absober water in cloth distillation is generally carried out mechanically for example using a tap. Mechanical flow rate regulation using a tap cannot produce a constant flow especially at a small flow rate. This study will overcome these problems by using flow settings based on microcontroller.

\section{Literature Review}

The performance of a solar energy distillation device is determined by the amount of clean water that can be produced, based on the variations used [1]. Many factors that influence the amount of distilled water produced include: the effectiveness of absorber in absorbing solar energy [2], the effectiveness of glass in condensing water vapor [3], the amount of mass / volume of water contained in distillation devices, the surface area of water to be distilled length of heating time, and temperature of water entering the distillation device [4]. Absorber must be made of material with good absorptivity of solar energy, to increase absorptivity generally the absorber is painted in black. The cover glass should not be too hot because if the glass is too hot the steam will be difficult to condense. The amount of mass / volume of water in a distillation device should not be too much because it will prolong the heating process. The flow rate that is too large will cause the evaporation process to be ineffective, but if it is too small then the distillation tool will be easily damaged due to overheating. Therefore, it is necessary 


\section{International Journal of Applied Sciences and Smart Technologies}

Volume 1, Issue 2, pages 129-146

p-ISSN 2655-8564, e-ISSN 2685-9432

to regulate a good mass flow rate. The setting of the mass flow rate commonly used is a mechanical controller using a tap. Mechanical water flow control has a disadvantage, namely the unstable water flow rate. This is due to the flow with the mechanical arrangement easily blocked by the presence of water vapor that appears on the valve tap. Basically this research aims to overcome the weaknesses in the mechanical water rate control system using a microcontroller based flow rate controller.

\section{Method}

Experiments are carried out indoors using lamp heat energy as a simulation of solar thermal energy. In experimental data retrieval, several variables used for analysis will be measured. These variables are: temperature absorber in the distillation model $\left(T_{w},{ }^{\circ} \mathrm{C}\right)$, glass temperature $\left(T_{C},{ }^{\circ} \mathrm{C}\right)$, lamp heat energy $\left(G_{T}, W / m^{2}\right)$, the amount of distilled water produced (md, liter), the area of distillation equipment $\left(A c, m^{2}\right)$ and cloth discharge (incoming discharge of distillation equipment; $Q$ liter/hour). In detail, the steps of this research experimentally are :

1. Prepare a distillation device namely a type of distillation cloth with insulated cloth (Figure 1).

2. Preparing measuring instruments to be used include temperature sensors, level sensors, solar meters, arduino microcontrollers, and stopwatches.

3. Regulate the discharge of cloth (the discharge into the distillation apparatus) is 0.3 liters/hour.

4. Record temperature absorber in the distillation model (T.w), glass temperature (T.C), amount of distilled water produced $\left(m_{u a p}\right)$ and heat energy from the infrared lamp $\left(G_{T}\right)$ every minutes for 8 hours.

5. Repeat steps 2, 3, and 4 with variations in the flow rate of 0.5 liters/hour and 1.2 liters/hour.

6. Perform data analysis compared to the results of distillation water and efficiency resulting from variations number 1,2 , and 3. 


\section{International Journal of Applied Sciences and Smart Technologies}

Volume 1, Issue 2, pages 129-146

p-ISSN 2655-8564, e-ISSN 2685-9432

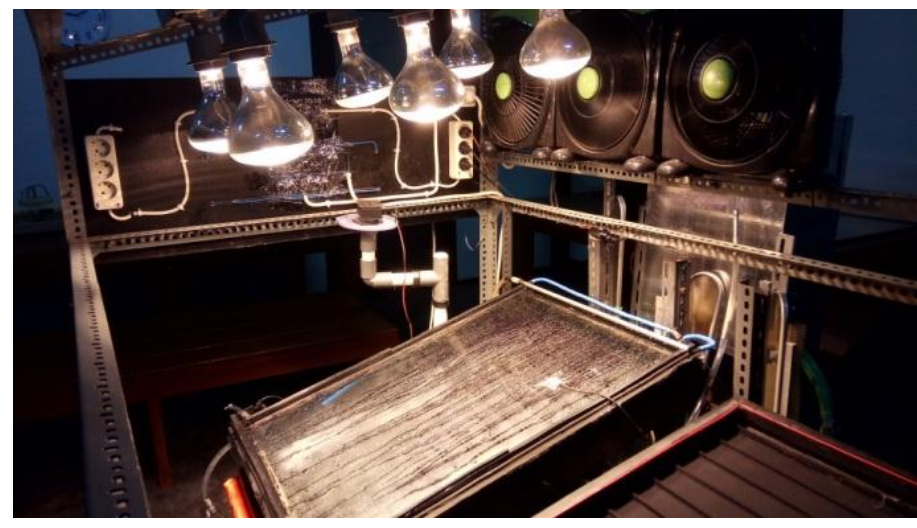

Figure 1. Distillation with fabric and cooler spray

Data collection for each variation was carried out for 3 days and within a day for 8 hours. Data recording is done by sensors arranged with a microcontroller, so data can be collected every minute. Data analysis and discussion of the phenomena that occur is done by making a comparison chart of the increase in water yield per 40 minutes for 8 hours of data collection for each variation. After data collection and data analysis is complete, the research is continued with the compilation of data results and processing, drawing conclusions and suggestions.

The efficiency of solar energy distillation equipment is defined as the ratio between the amount of energy used in the evaporation process of water and the amount of solar radiation that comes during a certain time. The efficiency of a distillation device consists of theoretical and actual efficiency. Theoretical efficiency ( $\eta$ theoretical) is defined as the ratio of the amount of energy used to raise the temperature of a number of water masses in a distillation device based on theoretical data (using solar thermal energy). Where as the actual efficiency ( $\eta$ actual) is defined as the ratio between the amount of energy used to raise the temperature of a number of water masses in a distillation device based on research data collection (using lamp heat energy). The actual efficiency ( $\eta$ actual) can be calculated by Equation 1 and with md is the result of distilled water (liter) is the discharged of cloth, hfg is latent heat of water $(\mathrm{J} / \mathrm{kg}), \mathrm{Ac}$ is the area of distillation $(\mathrm{kg}), G_{T}$ is heat energy lamp $\left(\mathrm{W} / \mathrm{m}^{2}\right)$.

$$
\eta_{\text {aktual }}=\frac{m d \cdot h f g}{A c \cdot \int_{0}^{t} G_{T} d t}
$$




\section{International Journal of Applied Sciences and Smart Technologies}

Volume 1, Issue 2, pages 129-146

p-ISSN 2655-8564, e-ISSN 2685-9432

The efficiency of the $\eta$ actual distillation tool can be calculated by md is the result of distilled water $(\mathrm{kg})$, hfg is the latent heat of evaporation $(\mathrm{J} / \mathrm{kg})$, Ac is the distillation area $\left(m^{2}\right)$, GT is the heat energy of the infrared lamp $\left(W / m^{2}\right)$, dt is heating time (seconds).

The control of water flow that will be used in this study is the arrangement of microcontroller and mechanical water flow (as a comparison). Figure 2 shows a block diagram of the water rate control system along with the data acquisition. The system consists of 3 inputs (flow speed setting, water level sensor, and real time clock). While the output is to drive the motor at the peristaltic pump. The function of this system is to control flow rate of water, read the water level that has been achieved, and save the results into memory.

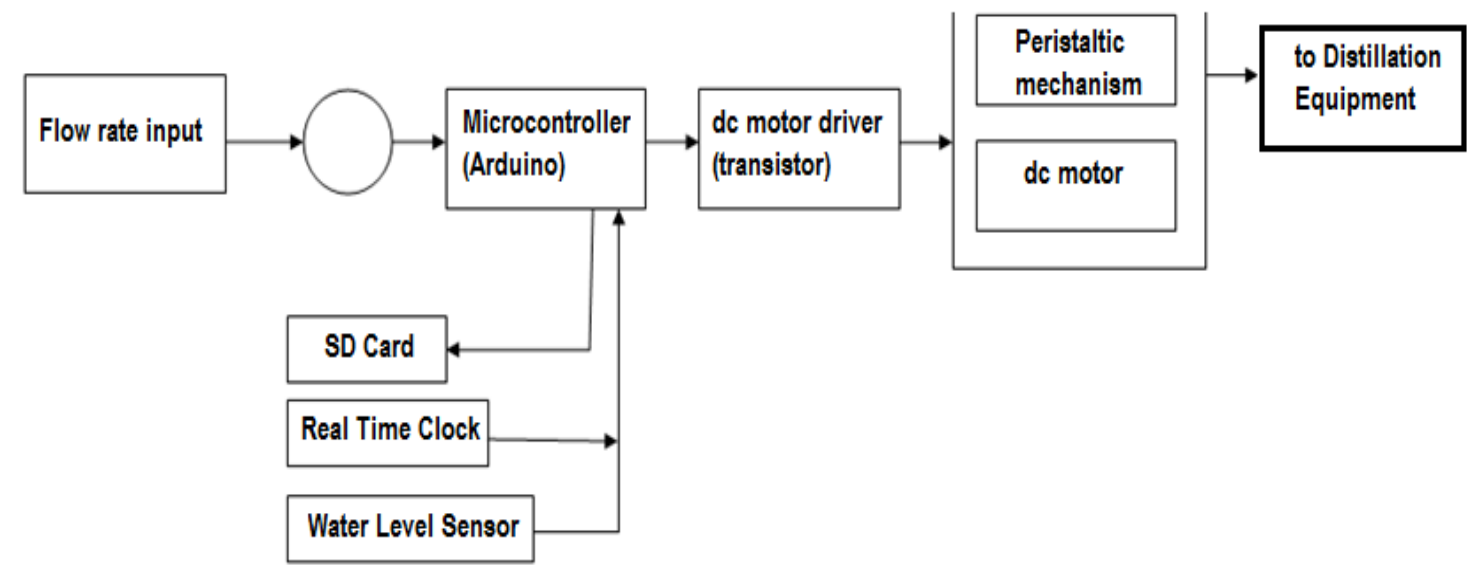

Figure 2. Block diagram of a water flow controller

A peristaltic pump is used in this study to regulate the water input rate (Figure 3) which is controlled by a microcontroller. The microcontroller used is ATMega 328 in the Arduino platform, which consists of hardware and software. The hardware consists of an on-board processor and $I / O$. While the software consists of the program and boot loader. In this system an Arduino Uno board which has 20 Digital Output and Input pin is used, which consists of pin $D 0$ to $D 13$ (14 pieces) and added pin $A 0-A 5$ (6 pieces). Pin $A 0-A 5$ can be used digitally as $D 14-D 19$ in the program. Especially for pin D0 and D1, they are used as communication line to computer [5]. 


\section{International Journal of Applied Sciences and Smart Technologies}

Volume 1, Issue 2, pages 129-146

p-ISSN 2655-8564, e-ISSN 2685-9432

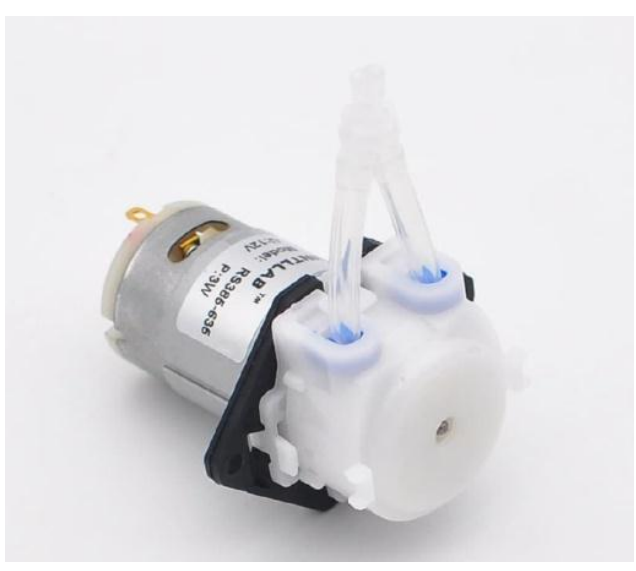

Figure 3. Physical appearance of a peristaltic pump

Peristaltic pumps are positive displacement pumps that are usually used to pump fluids. This pump works by moving a wheel that presses a flexible hose to move fluid [6]. Figure 4 shows the part in the peristaltic mechanism.

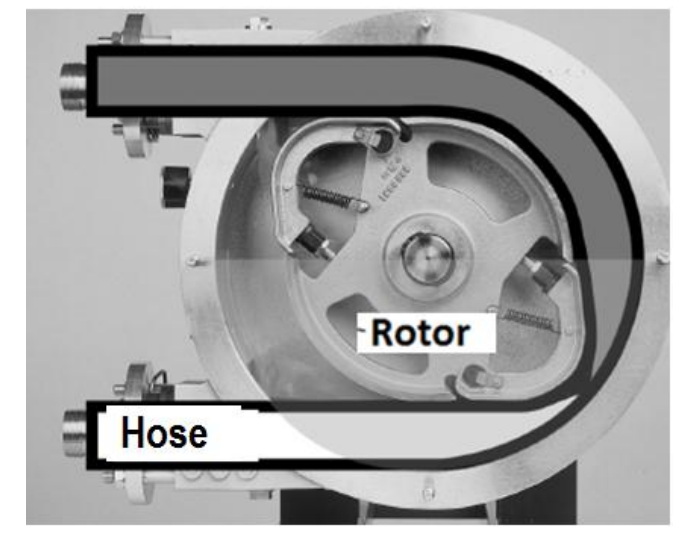

Figure 4. Inner view of peristaltic mechanism

Several studies related to regulating the flow of water with small discharges have been widely carried out. For example to regulate the flow of hospital equipment such as infusion pumps or flow control in the desalination process. Caraballo [7] has conducted research on the use of peristaltic motors with Arduino microcontroller boards to regulate water flow in the desalination process at a low cost. Banerjee et al. [8] also used a microcontroller and peristaltic pump on a dispenser system for mixing 2 types of microfluidic fluid. 


\section{International Journal of Applied Sciences and Smart Technologies}

Volume 1, Issue 2, pages 129-146

p-ISSN 2655-8564, e-ISSN 2685-9432

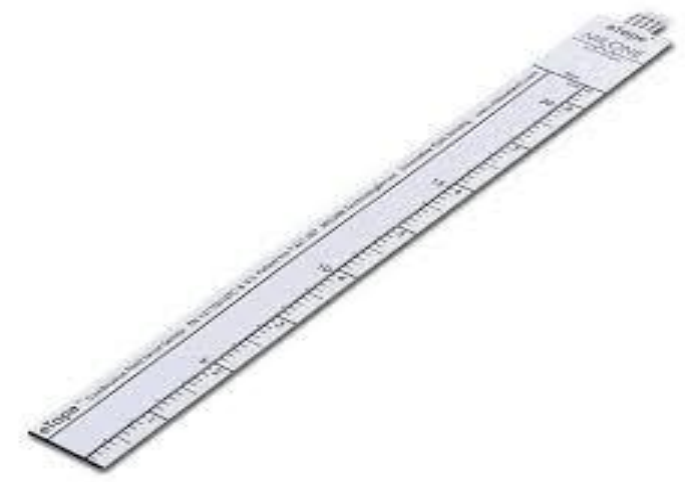

Figure 5. Physical appearance of eTape sensor

The water rate control system made in this study is open loop, so the accuracy of the results depends on calibration. The way the water rate control system works is as follows: potentiometer is used to adjust the amount of input voltage to the microcontroller (0-5 volts). Based on the input voltage the microcontroller will regulate the output voltage to the motor. The size of the voltage given to the motor will determine the motor's rotational speed. The Pulse Width Modulation (PWM) signal with a value of $0-1023$ from Arduino will determine the value of the voltage $(0-12$ volts) given to the motor, the greater the voltage, the faster the motor rotation. The output current of the microcontroller is relatively small (maximum $40 \mathrm{~mA}$ ). In order to be strong enough to move the motor, the analog output current of the microcontroller must be amplified, in this case using a transistor as an amplifier. The rotation of the DC motor will move the peristaltic mechanism (pulse suppression). For data retrieval (data logging), a memory module (SD Card) is added to the microcontroller. Real Time Clock (RTC) module is also added to provide real time values. While the water level is read by the eTape water level sensor. eTape from Miletone Technologies is a solid state sensor for measuring fluid height [9]. The eTape liquid level sensor is an innovative solid state sensor that does not use mechanical buoys as in general, but uses printed electronics. eTape gets hydrostatic pressure by the fluid where it is immersed, and produces a change in resistance corresponding to the distance from the top of the sensor to the surface of the fluid. The physical form of the eTape sensor is shown in Figure 5. 


\section{International Journal of Applied Sciences and Smart Technologies}

Volume 1, Issue 2, pages 129-146

p-ISSN 2655-8564, e-ISSN 2685-9432

E-tape can be modeled as a variable resistor $(60-550 \Omega \pm 20 \%)$. In operation, when the liquid level rises the resistance will decrease. If the water level drops resistance will rise. The typical output characteristics of the eTape sensor are shown in Figure 6 below

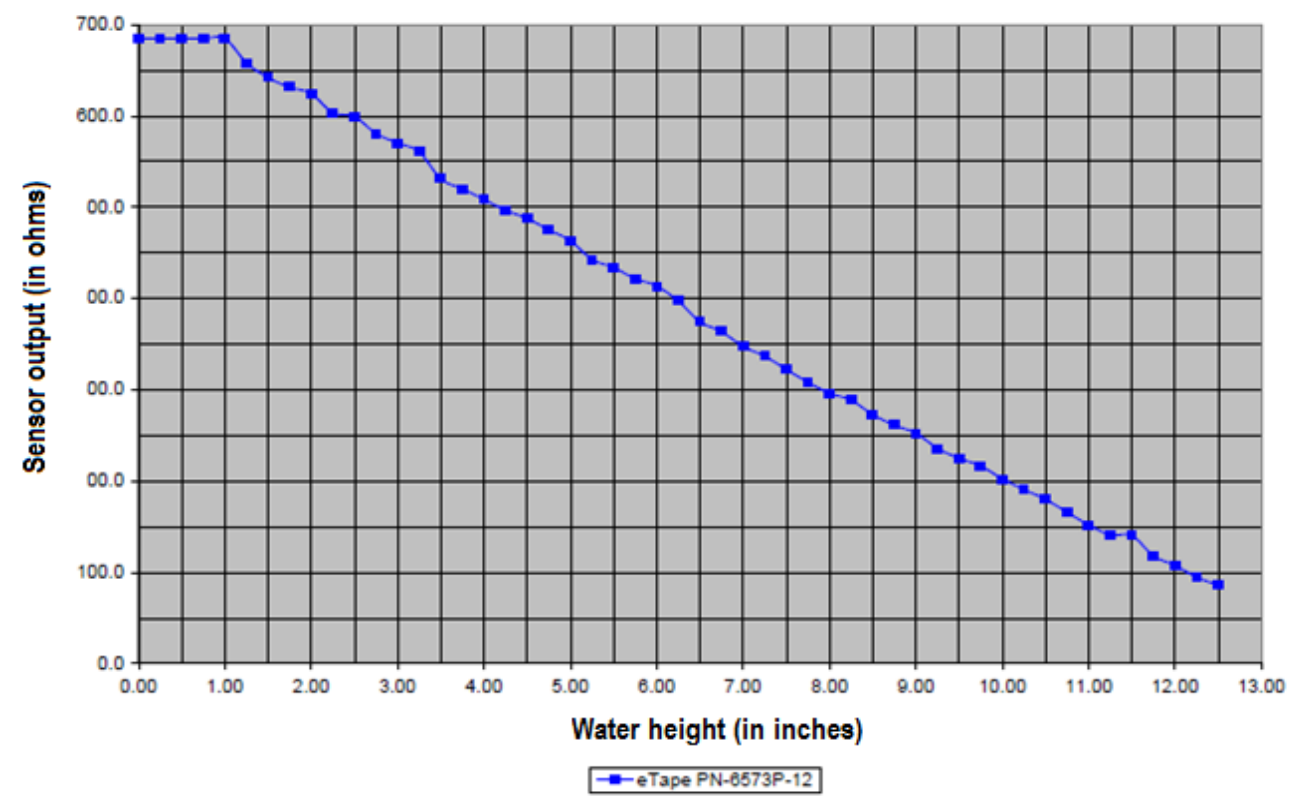

Figure 6. Plot of water height vs resistance of an eTape sensor

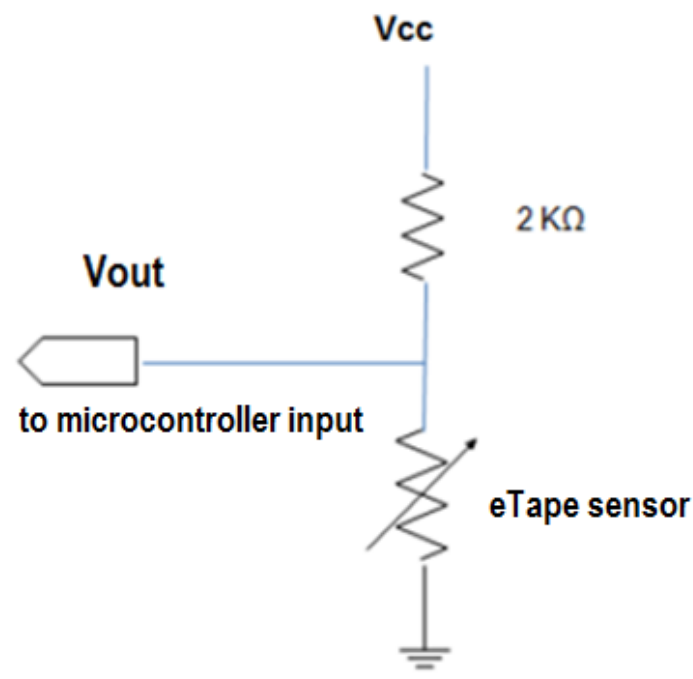

Figure 7. Voltage divider circuit with an eTape sensor 


\section{International Journal of Applied Sciences and Smart Technologies}

Volume 1, Issue 2, pages 129-146

p-ISSN 2655-8564, e-ISSN 2685-9432

Figure 7 shows how eTape sensor installation on the network. At this circuit, the voltage is proportional to the resistance of he eTape sensor, thus :

$$
\text { Vout }=[\text { Vcc x R eTape }] /[2 K \Omega+R \text { eTape }]
$$

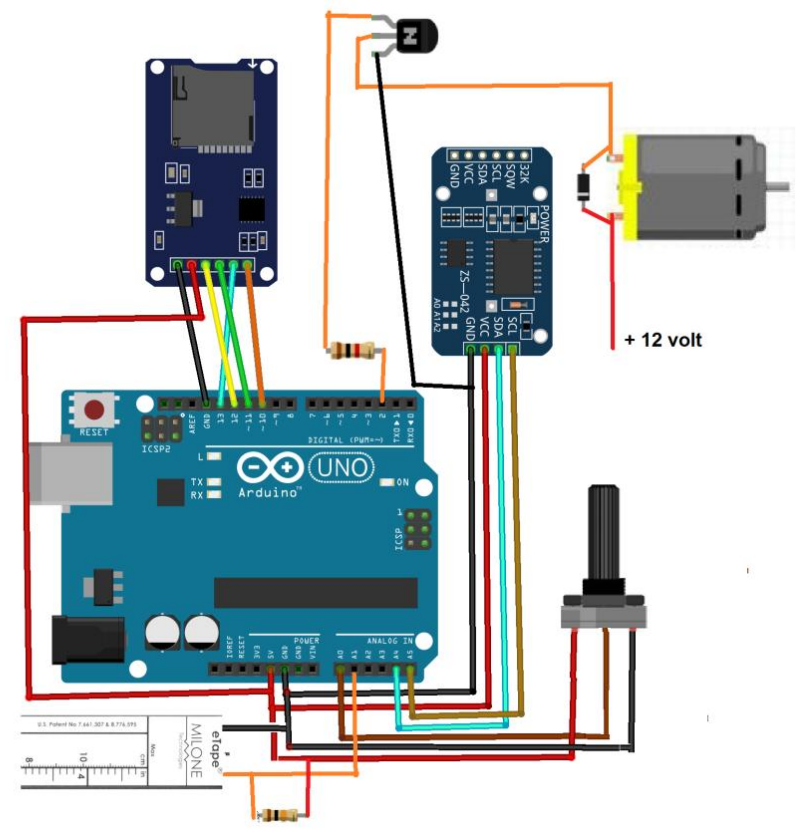

Figure 8. Water flow rate control and data acquisition circuit 


\section{International Journal of Applied Sciences and Smart Technologies}

Volume 1, Issue 2, pages 129-146

p-ISSN 2655-8564, e-ISSN 2685-9432

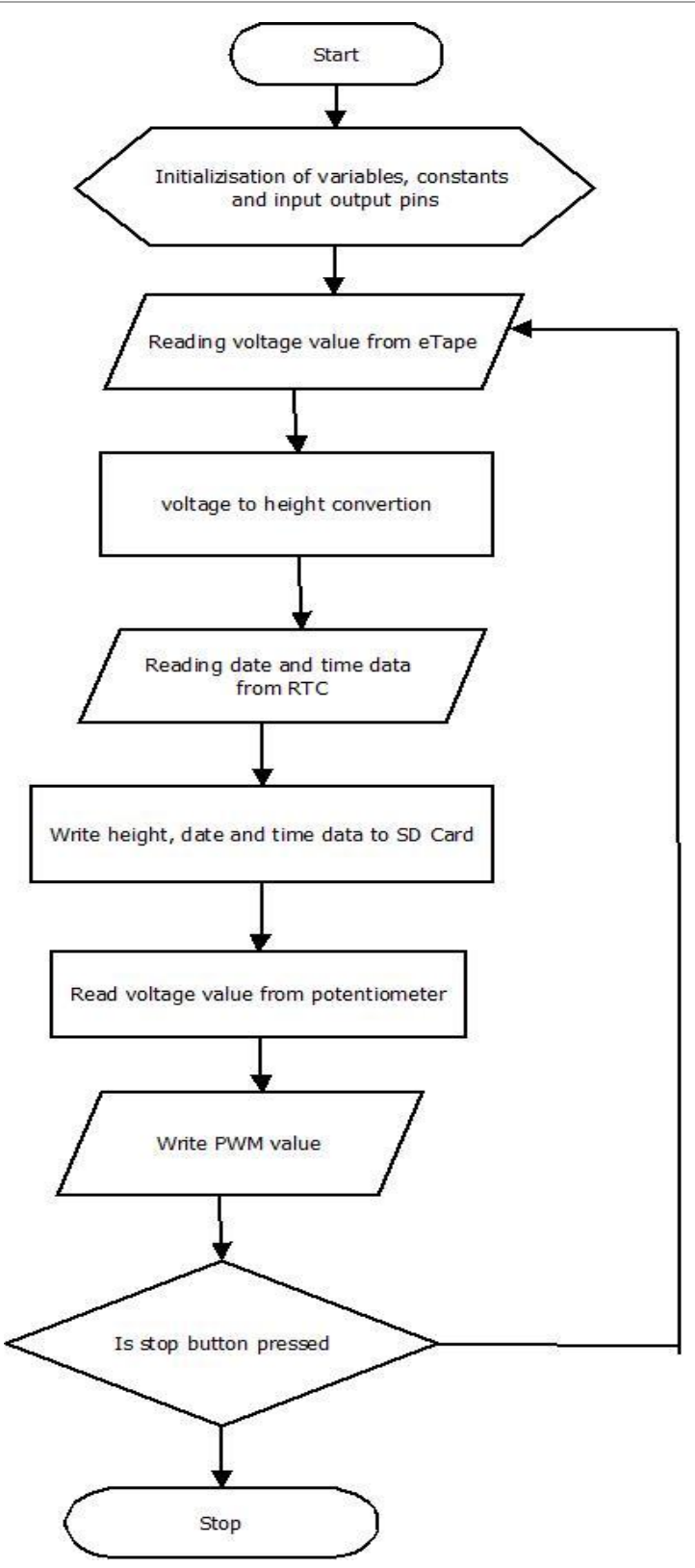

Figure 9. Flowchart of flow rate control

The electronic circuit for controlling water rate and data acquisition is shown in Figure 8. While the flow diagram of how the system works is shown in Figure 9.

\section{Results and Discussion}

The results achieved by this study are the completion of initial data retrieval. Model enhancements have also been made. The problem with the creation of a water rate 


\section{International Journal of Applied Sciences and Smart Technologies}

Volume 1, Issue 2, pages 129-146

p-ISSN 2655-8564, e-ISSN 2685-9432

control model is the small motor torque at low speed. This is because the current entering the pump motor is still low while the voltage is reduced to reduce motor rotation. This problem causes the motor to not be strong enough to pump at low speeds so that small discharges are difficult to achieve. This problem can be overcome by adding obstacles to the suction hose. The obstacles used are cloth. The fabric resistance allows the pump to produce a small discharge at a rotation that is not too small.

The results of data retrieval using the model have shown results in accordance with the initial hypothesis. The results of data collection showed that the results of distillation water using the control of the water rate were higher than the model without control of the water rate. The results of data collection can be seen in Table 1.

Table 1. Distillation output and efficiency for various flow rate

\begin{tabular}{|c|c|c|c|c|c|c|c|c|c|c|c|c|}
\hline \multirow{3}{*}{ 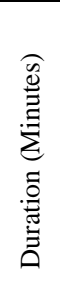 } & \multicolumn{6}{|c|}{ Distillation output $(\mathrm{kg})$} & \multicolumn{6}{|c|}{ Efficiency (\%) } \\
\hline & \multicolumn{2}{|c|}{$\begin{array}{c}\text { First flow rate } \\
0,3 \mathrm{l} / \text { hour }\end{array}$} & \multicolumn{2}{|c|}{$\begin{array}{c}\text { First flow rate } \\
0,5 \mathrm{l} / \text { hour }\end{array}$} & \multicolumn{2}{|c|}{$\begin{array}{c}\text { First flow rate } \\
1,2 l / \text { hour }\end{array}$} & \multicolumn{2}{|c|}{$\begin{array}{c}\text { First flow rate } \\
0,3 l / \text { hour }\end{array}$} & \multicolumn{2}{|c|}{$\begin{array}{c}\text { First flow rate } \\
0,5 \mathrm{l} / \text { hour } \\
\end{array}$} & \multicolumn{2}{|c|}{$\begin{array}{c}\text { First flow rate } \\
1,2 l / \text { hour } \\
\end{array}$} \\
\hline & 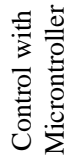 & 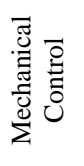 & 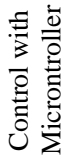 & 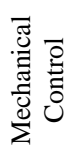 & 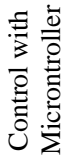 & 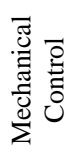 & 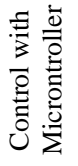 & 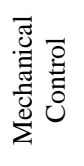 & 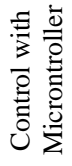 & 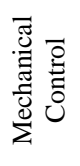 & 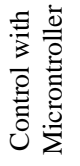 & 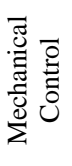 \\
\hline 40 & 0.000 & 0.000 & 0.000 & 0.000 & 0.000 & 0.000 & $1 \%$ & $0 \%$ & $0 \%$ & $0 \%$ & $0 \%$ & $0 \%$ \\
\hline 80 & 0.000 & 0.000 & 0.000 & 0.000 & 0.000 & 0.000 & $0 \%$ & $0 \%$ & $0 \%$ & $0 \%$ & $0 \%$ & $0 \%$ \\
\hline 120 & 0.198 & 0.000 & 0.031 & 0.010 & 0.013 & 0.000 & $21 \%$ & $0 \%$ & $3 \%$ & $1 \%$ & $1 \%$ & $0 \%$ \\
\hline 160 & 0.315 & 0.000 & 0.279 & 0.084 & 0.243 & 0.027 & $25 \%$ & $0 \%$ & $22 \%$ & 7\% & $19 \%$ & $2 \%$ \\
\hline 200 & 0.629 & 0.000 & 0.346 & 0.105 & 0.288 & 0.283 & $40 \%$ & $0 \%$ & $22 \%$ & $7 \%$ & $18 \%$ & $18 \%$ \\
\hline 240 & 0.791 & 0.000 & 0.575 & 0.174 & 0.503 & 0.360 & $42 \%$ & $0 \%$ & $30 \%$ & $9 \%$ & $26 \%$ & $19 \%$ \\
\hline 280 & 1.056 & 0.000 & 0.751 & 0.227 & 0.661 & 0.616 & $48 \%$ & $0 \%$ & $34 \%$ & $10 \%$ & $30 \%$ & $28 \%$ \\
\hline 320 & 1.285 & 0.000 & 0.899 & 0.272 & 0.948 & 0.827 & $51 \%$ & $0 \%$ & $35 \%$ & $11 \%$ & $37 \%$ & $33 \%$ \\
\hline 360 & 1.501 & 0.000 & 1.182 & 0.358 & 1.164 & 1.002 & $53 \%$ & $0 \%$ & $41 \%$ & $12 \%$ & $40 \%$ & $35 \%$ \\
\hline 400 & 2.040 & 0.189 & 1.344 & 0.407 & 1.380 & 1.231 & $64 \%$ & $6 \%$ & $42 \%$ & $13 \%$ & $43 \%$ & $39 \%$ \\
\hline 440 & 2.324 & 0.324 & 1.658 & 0.503 & 1.856 & 1.456 & $67 \%$ & $9 \%$ & $47 \%$ & $14 \%$ & $53 \%$ & $42 \%$ \\
\hline 480 & 2.521 & 0.404 & 2.031 & 0.616 & 1.955 & 1.798 & $66 \%$ & $11 \%$ & $53 \%$ & $16 \%$ & $51 \%$ & $47 \%$ \\
\hline
\end{tabular}

Figure 10 shows the results of distillation water at various water flow rates of 0.3 liters/hour. The water distillation model that uses a water flow rate controller with a microcontroller can produce far more distilled water. Up to minutes to 365 distillation models that use mechanical settings (taps) do not produce distilled water. This is due to the occurrence of problems in the mechanical flow settings. A common problem especially at small flow rates is the cessation of water flow that will enter the distillation model. The cessation of flow in the mechanical control, especially in small streams, is due to the presence of water vapor which clogs the canal. 


\section{International Journal of Applied Sciences and Smart Technologies}

Volume 1, Issue 2, pages 129-146

p-ISSN 2655-8564, e-ISSN 2685-9432

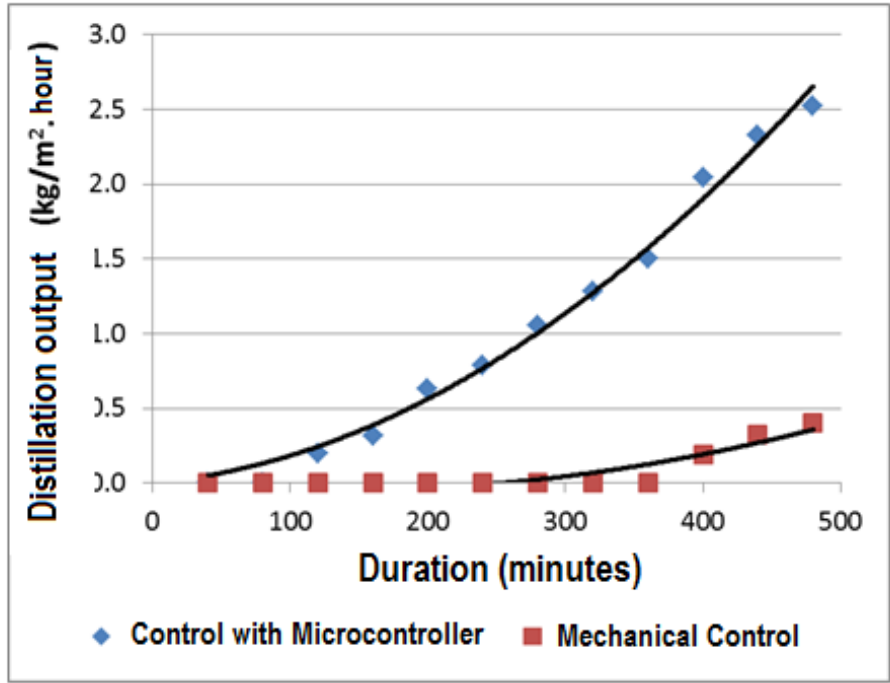

Figure 10. Comparison of distillation output at flow rateof 0,3 liter/hour

At the water flow rate of 0.5 liters /hour or in variation number 2 (Figure 11), the results of distilled water models with water flow rate controller using microcontroller is bigger than the distillation models without adjusting the flow rate with microcontroller or using mechanical controller (faucet). In contrast to variation number 1, it appears that a water distillation model with a mechanical control has produced distilled water in the 150th minute. This is because the water flow rate of distillation in variation number 2 is greater than variation number 1 . At the higher water flow rate there is fewer problem compared with mechanical flow rate control at the smaller flow rate. The problem of mechanical control in variation number 2 is to reduce the water flow rate to the initial setting. The reduced flow is generally also caused by the appearance of water vapor which blocks the flow of water that will enter the distillation model. 
International Journal of Applied Sciences and Smart Technologies

Volume 1, Issue 2, pages 129-146

p-ISSN 2655-8564, e-ISSN 2685-9432

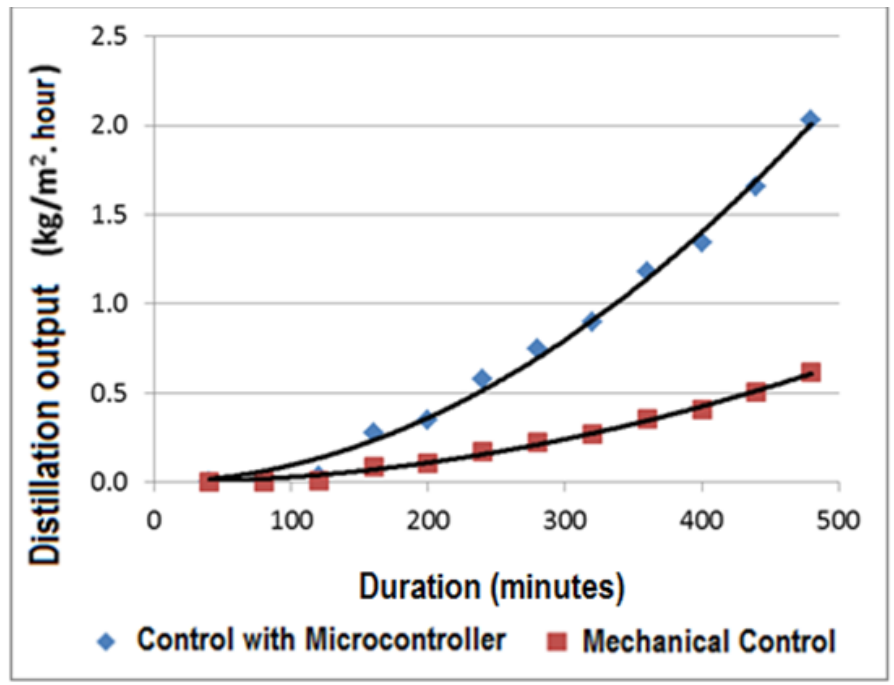

Figure 11. Comparison of distillation output at flow rate of 0,5 liter/hour

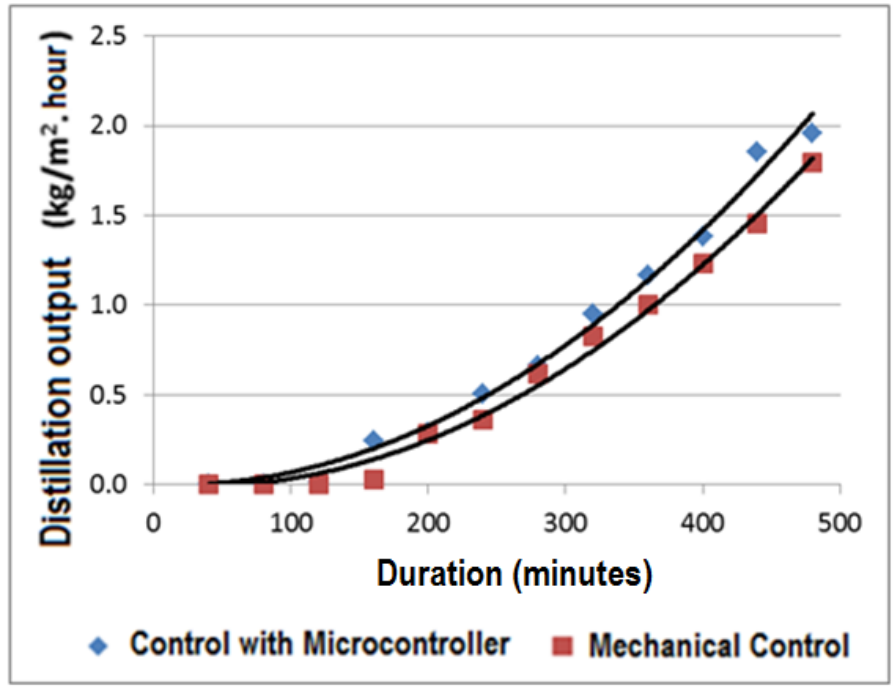

Figure 12. Comparison of distillation output at flow rate of 1,2 liter/hour 


\section{International Journal of Applied Sciences and Smart Technologies}

Volume 1, Issue 2, pages 129-146

p-ISSN 2655-8564, e-ISSN 2685-9432

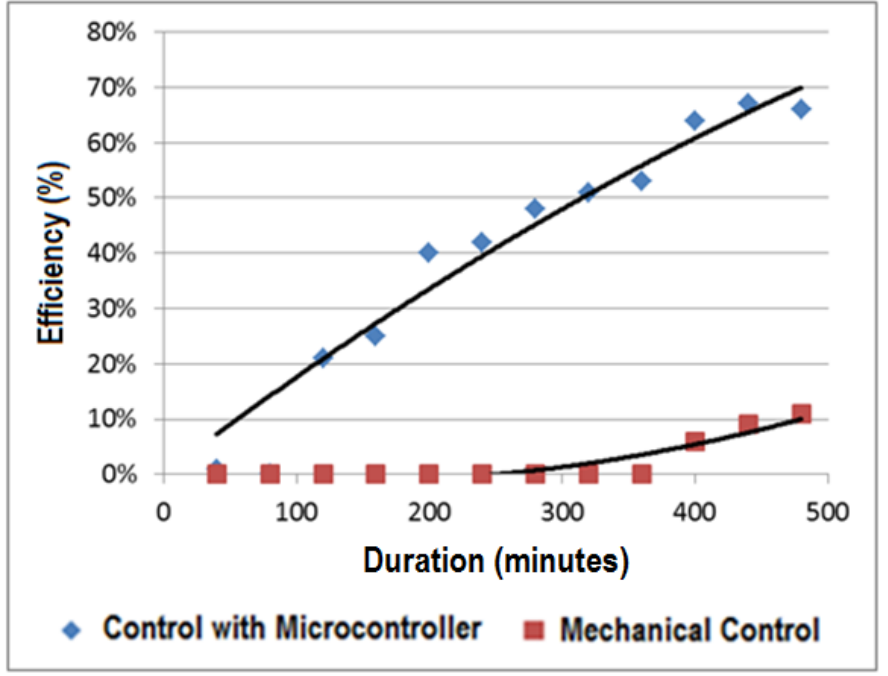

Figure 13. Efficiency comparison of a distillation model at flow rate of 0,3 liter/hour

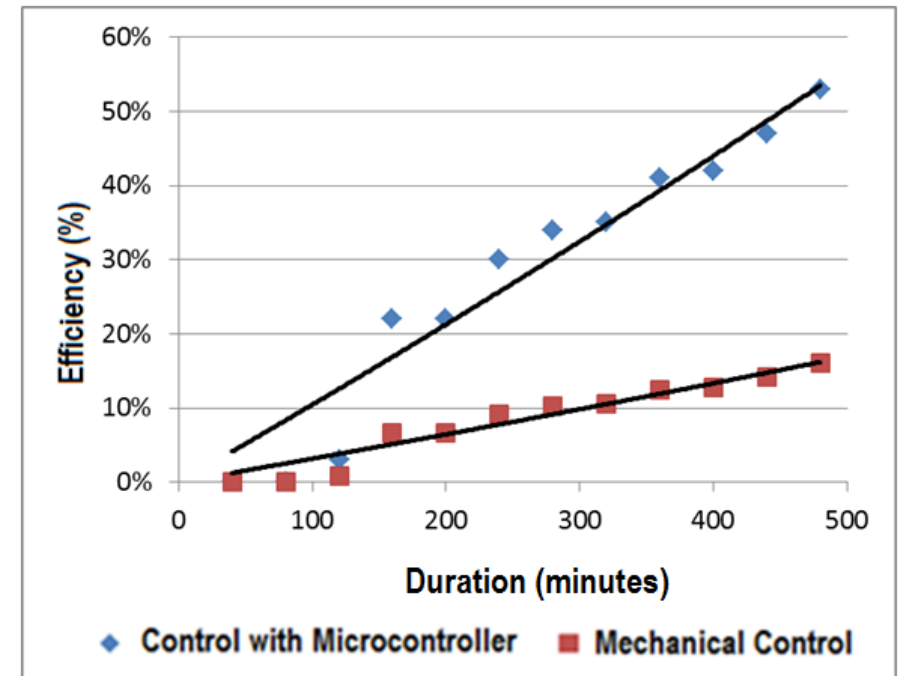

Figure 14. Efficiency comparison of a distillation model at flow rate of 0,5 liter/hour

In variation number 3 by setting the initial flow rate of 1.2 liters/hour it is seen that the distillation model with a mechanical arrangement begins to produce distilled water from the 90th minute (Figure 12). In variation number 3 the results of distillation of water models with microcontroller settings still produce more distilled water than the distillation model with mechanical settings. There is problem with mechanical control, when the water flow rate is large enough, the water flow rate increases from the initial 


\section{International Journal of Applied Sciences and Smart Technologies}

Volume 1, Issue 2, pages 129-146

p-ISSN 2655-8564, e-ISSN 2685-9432

setting. This causes the evaporation process is not optimal so that the results of distillation water are also small.

The efficiency produced in the three variations shows a linear value with the results of distilled water produced by each variation. This can be seen from Figures 13, 14, and 15.

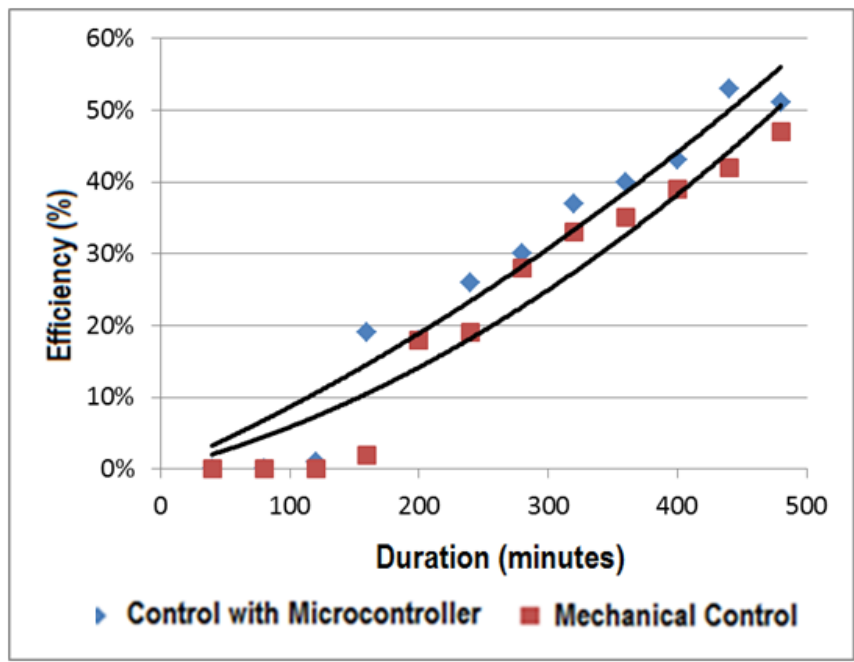

Figure 15. Efficiency comparison of a distillation model at flow rate of 1,2 liter/hour

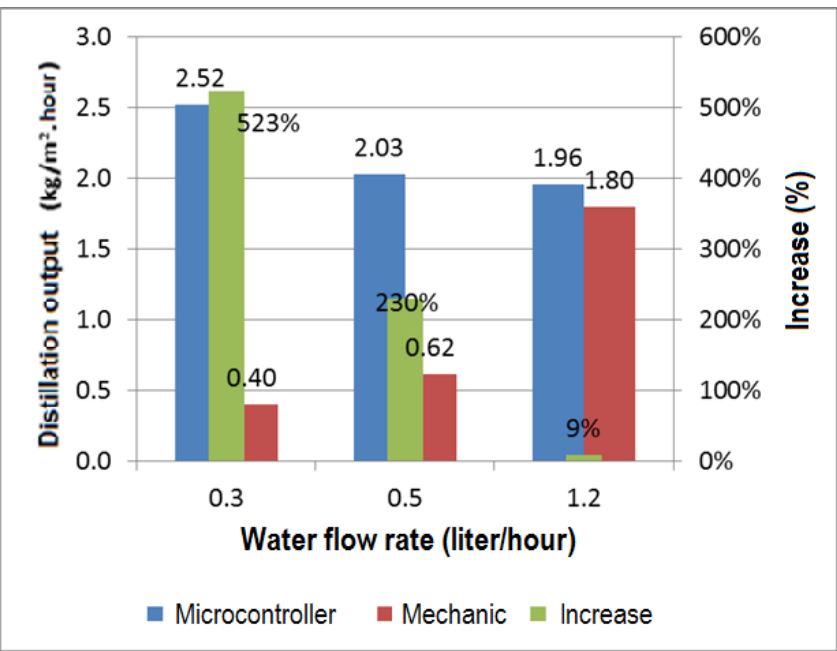

Figure 16. Comparison of distillation output at the flow rate of 0,$3 ; 0,5$ and 1,2 liter/hour 


\section{International Journal of Applied Sciences and Smart Technologies}

Volume 1, Issue 2, pages 129-146

p-ISSN 2655-8564, e-ISSN 2685-9432

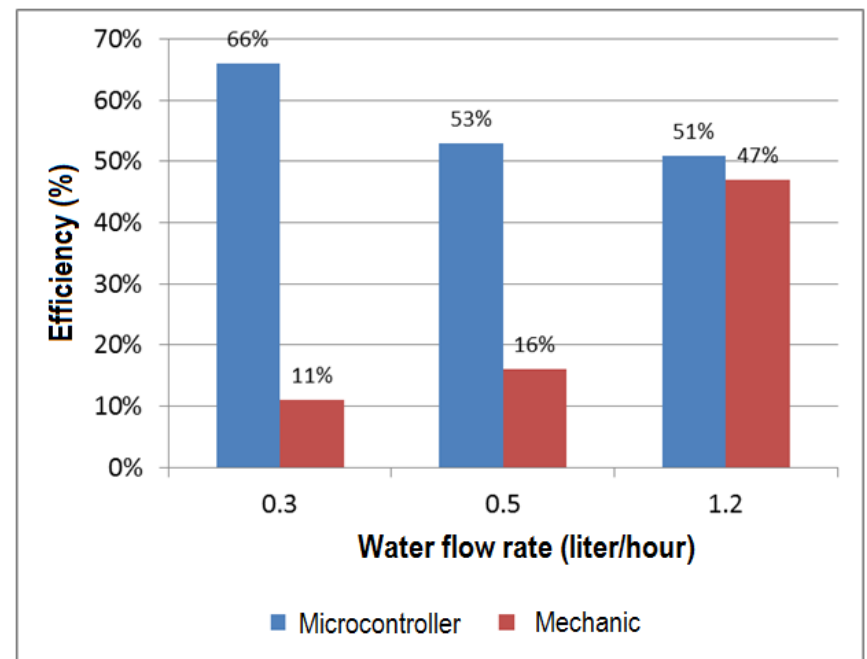

Figure 17. Efficiency comparison of distillation output at flow rate of 0,$3 ; 0,5$ and

1,2 liter/hour

In general, the increase in distillation water yield due to the use of microcontrollerbased intake of water flow can be seen in Figure 16. The biggest increase in distillation water results with microcontroller-based water flow control compared to mechanical settings is $523 \%$. The biggest increase occurs at the planned initial intake water flow of 0.3 liters /hour (water flow rate enter the smallest distillation). The highest efficiency produced by microcontroller-based distillation is $66 \%$ at a water flow rate of 0.3 liters /hour (Figure 17).

\section{Conclusion}

The conclusion that can be taken in general this research is that the results of distillation water using microcontroller-based water rate control is a maximum of $523 \%$ compared to the model sans water rate control 0.3 liters/hour, with distillation efficiency of $66 \%$. From the results of this study it can also be concluded that microcontroller based water speed control is more stable than mechanical water flow control, especially in small flow. 


\section{International Journal of Applied Sciences and Smart Technologies}

Volume 1, Issue 2, pages 129-146

p-ISSN 2655-8564, e-ISSN 2685-9432

\section{Acknowledgements}

This work would not have been possible without the financial support from DP2M DIKTI which has funded this Penelitian Dosen Pemula project. Thank you to the relevant parties in the process of conducting this research, DP2M DIKTI, Politeknik Mekatronika Sanata Dharma which have supported this research.

\section{References}

[1] H. M. Ahmed, A. K. Al Taie, and M. Almea, "Solar water distillation with a cooling tube," International Renewable Energy Congress, pages 6-10, November 2010 .

[2] T. J. Jansen, Teknologi Rekayasa Surya, PT Pradnya Paramita, Jakarta, 1995.

[3] A. J. N. Khalifa and A. M. Hamood, "Experimental validation and enhancement of some solar still performance correlations," Desalination and Water Treatment, 4 (13), 311-315, 2009.

[4] D. W. Medugu and L. G. Ndatuwong, "Theoretical analysis of water distillation using solar still," International Journal of Physical Sciences, 4 (11), 705-712, 2009.

[5] M. Banzi and M. Shiloh, Getting Started with Arduino: the Open Source Electronics Prototyping Platform, Maker Media, Sebastopol, 2015.

[6] M. W. Volk, Pump Characteristics and Applications 2nd Edition, CRC Press, Boca Raton, 2005.

[7] G. Caraballo, “An arduino based control system for a brackish water desalination plant," Master Thesis, University of North Texas, Denton, 2015.

[8] N. Banerjee, S. Mukherjee, A. Mitra, A. Sanyal, and S.T Mandal, "Arduino based liquid dispensor system using peristaltic pump," B. S. Project, West Bengal University of Technology, Kolkata, 2017.

[9] https://milonetech.com/p/about-etape (Accessed on 25-05-2019). 